\title{
The Economics of NPA Behaviour in the Global Economy
}

\section{Samayita B*}

Department of Quantitative Finance, Ramanujan School of Mathematical Sciences, Pondicherry University, Puducherry, India

\begin{abstract}
NPA is a vexing problem which has been globally effecting economies for a long time. The mounting NPA levels in banks and financial institutions calls for earnest attention and immediate action as it is a menace to the public. Bank credit motivates economic growth of the country and any obstruction in the undisturbed flow of credit, a significant cause for which is the heightened NPA levels, is detrimental to the health of the economy. The issue of Non-performing assets (NPA), the blatant cause of the current global financial crisis, has been drawing the attention of all and sundry for its rapid manifestation in the present financial structure. The primary objective of this paper is to understand the economic and mathematical models backing the phenomenon of NPAs. In this regard we have utilised the basic Keynesian economics to study behaviour of NPAs at the macroeconomic level and hence make viable conclusions and give policy suggestions regarding the same.
\end{abstract}

Keywords: Non-performing assets; Keynesian macroeconomics; Mathematical economics; Macroeconomic models; Banking and finance

\section{Macroeconomics of Non-Performing Asset in Commercial Bank}

We intended to discuss on the impact of creation of NonPerforming Asset (NPA) with commercial bank on the macroeconomic health of an economic system along with an appraisal of the efficacy of current framework of mitigating this malady. The loans extended by a commercial bank are assets in the sense that they earn interest income and therefore the term Non-Performing is used to identify the loans which are not refinanced in within the due period of time; thereby failing to generate income [1]. Now given the role of the banking sector in the mobilisation of financial resources towards investment, accumulation of Non-performing asset is appalling as it will turn the banks insolvent and thereby will hurt the momentum of investment across the economy tremendously and so the economic growth.

\section{Model I}

In order to explicate the deleterious impact of burgeoning NPA on the macroeconomic stability of an economic system a model has been devised based on the modified Closed Economy IS-LM framework where the traditional money market has been replaced by the debt market led by the commercial banks. In this model the economy system will be seen comprising of real sector based on the goods market and the financial sector based on the loan market wherein the interest rate gets determined from loan market equilibrium and this in turn calibrates the investment demand enabling an interaction between the real and financial sector.

Let us now first analyse the loan market where the supply new loans $\left(\mathrm{L}_{\mathrm{S}}\right)$ is generated by the accumulation deposits(D) made by nonbank public with the commercial banks net of reserves to be held by commercial banks with the central bank. Thus we can define the supply new loan as $\mathrm{L}_{\mathrm{St}}=\mathrm{dD}_{\mathrm{t}}-\mathrm{dR}_{\mathrm{t}}+\mathrm{f}\left(\mathrm{i}_{\mathrm{t}}-\mathrm{i}_{\mathrm{g}}\right)$ where $\mathrm{dD}_{\mathrm{t}}, \mathrm{dR}_{\mathrm{t}}$ respectively denote the changes in the deposit stock and total reserves held by the commercial banks with Central Bank in period t. Now given that $r$ is the Required Reserve Ratio we can write that $\mathrm{R}_{t}=\mathrm{D}_{\mathrm{t}} \mathrm{r}$ and assuming that credit extended by the Central Bank goes to finance Government expenditure $\left(G_{t}\right)$, it can be posited that $d_{t}=G_{t}$ in the light of the Central Bank's balance sheet identity i.e., the change in the liability $\left(\mathrm{dR}_{t}\right)$ is equal to change in the asset which is G. Thus we get supply side of loan market as $\mathrm{L}_{\mathrm{St}}=(1-\mathrm{r}) \mathrm{dR}_{\mathrm{t}} / \mathrm{r}=(1-\mathrm{r}) \mathrm{G}_{\mathrm{t}} / \mathrm{r}+\mathrm{f}\left(\mathrm{i}_{\mathrm{t}}-\mathrm{i}_{\mathrm{g}}\right)$.

Now the demand side of the loan comes the demand for investment which is determined by of interest rate (i) and profit expectation $(\beta)$ i.e. $L_{D t}=I\left(i_{t}, \beta\right)$. Therefore at equilibrium in the loan market we have:

$$
I\left(i_{t}, \beta\right)=(1-r) G_{t} / r+f\left(i_{t}-i_{g}\right)
$$

the condition determining equilibrium interest rate as depicted in the Figure 1 where $i_{t}{ }_{t}^{*}$ is the equilibrium interest rate.

Now the good market remains as that in the traditional IS-LM model where in the equilibrium condition is given by $Y_{t}=A D_{t}=C\left(Y_{t}\right.$ $\left.-T_{t}\right)+I\left(i_{t}, \beta\right)+G_{t}$. Now replacing $I_{t}$ in the goods market equilibrium condition by its expression from loan market equilibrium we have the modified goods market equilibrium condition as

$$
Y_{t}=C\left(Y_{t}-T_{t}+G_{t} / r\right.
$$

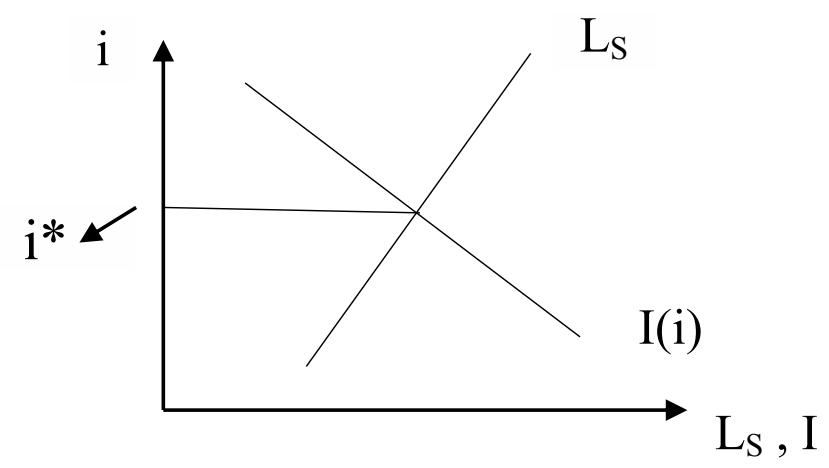

Figure 1: Demand-supply equilibrium in the loan market.

*Corresponding author: Samayita B, Department of Quantitative Finance Ramanujan School of Mathematical Sciences, Pondicherry University, Puducherry, India, Tel: 0442254 3100; E-mail: sbhattacharya1995@gmail.com

Received November 01, 2017; Accepted November 27, 2017; Published December 04, 2017

Citation: Samayita B (2017) The Economics of NPA Behaviour in the Global Economy. J Glob Econ 5: 272. doi: 10.4172/2375-4389.1000272

Copyright: (c) 2017 Samayita B. This is an open-access article distributed under the terms of the Creative Commons Attribution License, which permits unrestricted use, distribution, and reproduction in any medium, provided the original author and source are credited. 
Thus the equilibrium output is $\mathrm{Y}^{\star}$ as illustrated in the Figure 2 .

Here in the above figure the goods market is in equilibrium at a point where $45^{\circ}$ line intersects the $\mathrm{AD}$ line generating the equilibrium output $\mathrm{Y}^{*}$ which therefore is a function of $\mathrm{G}, \mathrm{T}$ and $\mathrm{r}$. Thus a rise $\mathrm{G}$ leads to an upward shift in the $\mathrm{AD}$ line indicating impact of expansionary Fiscal Policy while a rise in $r$ leads to the downward shift in AD line implying the contracting effect of tight monetary on the real aggregate output and income [2]. The multiplier effects of rise in $G(k)$ can determined by differentiating totally eqn. (2) as

$$
\begin{aligned}
& d Y=C^{\prime} d Y+d G / r \\
& \text { or } d Y / d G=[(1-C) / r]=k>0 \text { since } 0<C^{\prime}<1 \text {. }
\end{aligned}
$$

Thus, government expenditure multiplier depends on the policy rate unlike it is normally.

Similarly, the negative multiplier effect of a fall in $\mathrm{r}$ is given by $\mathrm{dY} /$ $\mathrm{dr}=(-)\left[1 / \mathrm{r}^{2}(1-\mathrm{C})\right] \mathrm{G}$; where $\mathrm{r}_{0}$ is the given Required Reserve Ratio.

\section{Intuition Behind the Multiplier Effects}

An increase in $G$ requires an increase in the borrowings of the Central Bank leading to the expansion of monetary base that leads to the fall in the interest on loans. As results the firms find more incentive to invest and thereby allows for the expansion $\mathrm{AD}$ and hence the equilibrium aggregate real output $\mathrm{Y}^{*}$. On the other hand, a cut in reserve ratio $r$ will lower the portion of increased deposit available to the commercial banks that to be held as reserve with the Central Bank leading to the expansion the commercial bank' credit creating capacity. This makes borrowing less costlier inducing more investment leading to the rise in the real aggregate output.

\section{Case of Non-Performing Asset}

To elucidate the impact of NPA on the macroeconomic condition we slightly modulate the framework discussed so far. The accumulation NPA will cripple the banks' credit creating capacity in terms of the provision that banks are keep to compensate the loss arising due to the defaults. Thus if $\mathrm{P}$ is the provision kept by the commercial banks for the loss due to NPA, the equation of the supply of new loans in period $t$ will get adjusted as

$L_{S t}=(1-r) G_{t} / r-P_{t}+f\left(i_{t}-i_{g}\right)$, where $P_{t}$ is the provision due to the in default on the new loans made in the period $t-1$. Now given that the

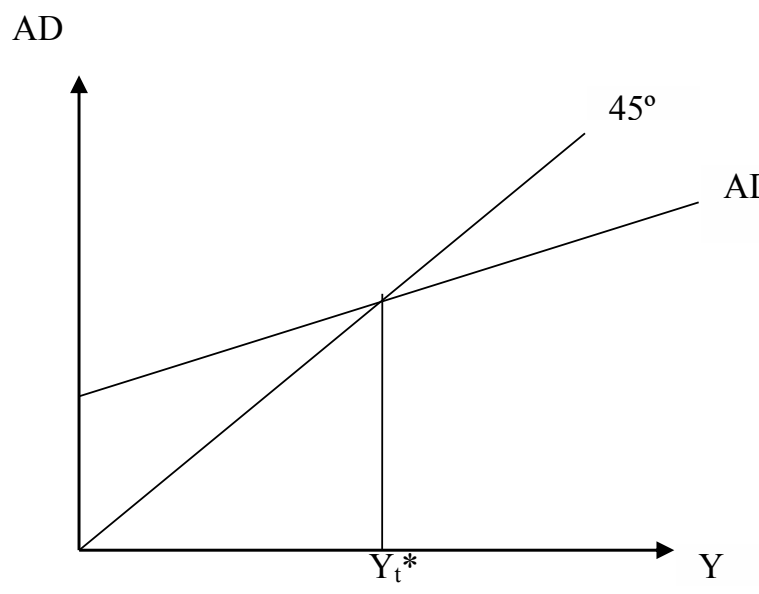

Figure 2: Equilibrium in the goods market. propensity on part of the firms to default on loans is determined by the state of aggregate demand in the sense that a contraction of $\mathrm{AD}$ and resultant recession in period $\mathrm{t}-1$ will not let the firms achieve the expected revenue and thereby will make it difficult for the firms to refinance the loans, one can think of the loss provision $\mathrm{P}$ being a decreasing function of previous output level $\mathrm{Y}_{\mathrm{t}-1}$, given that the real aggregate output is demand determined [3]. Moreover, there may be some other reasons for the rise in loss provision such as introduction of more stringent norms related to banking supervision, corporate failure with domestic firms due to increased competition from foreign counterparts with advanced technology and greater financial might, moral hazard related to undue discretionary favour in extending credit like sanctioning loans to the firms carrying negative credit rating etc. Accordingly we have the revised loan market equilibrium condition with $\mathrm{P}_{\mathrm{t}}=\mathrm{P}\left(\mathrm{Y}_{\mathrm{t}-1}, \varphi\right) ; \mathrm{P}<0$ :

$$
I\left(i_{t}, \beta\right)=(1-r) G_{t} / r-P_{t}+f\left(i_{t}-i_{g}\right) \text {. }
$$

Now the determination of $i_{t}^{*}$ can be explained as: for given level of equilibrium $Y_{-1}$ determined from the goods market, the supply of new loans will interact with the investment demand to determine $i_{t}^{*}$. As illustrated in Figure 3 that in presence of NPA the schedule for the supply of new loans will shift to the left from $\mathrm{L}_{\mathrm{St}}$ to $\mathrm{L}_{\mathrm{St}}$ leading to the rise in the equilibrium interest rate from $i_{t}{ }^{*}$ to $i_{t}{ }^{*}$.

Thus increase in interest rate will retard the momentum of investment affecting the production and real aggregate output. As shown in Figure 4, inclusion of $\mathrm{P}$ into the loan market equilibrium makes aggregate demand schedule $A D{ }_{t}=C\left(Y_{t}-T_{t}\right)+G_{t} / r-P\left(Y_{t-1}, \varphi\right)$ flatter than it is otherwise and thus results in the lowering of the equilibrium real aggregate output from $Y_{t}^{*}$ from $Y_{t}^{* *}$ (Figure 4). Thus accumulation leads to the contraction of real output and thereby can catapult the economy into recession and the real aggregate output in the modified goods market equilibrium becomes a function of output of the previous year $\left(\mathrm{Y}_{\mathrm{t}-1}\right)$ given everything else remaining unchanged. Therefore, what follows is that:

$$
\mathrm{Y}_{\mathrm{t}}=\mathrm{F}\left(\mathrm{Y}_{\mathrm{t}-1,}, \varphi, \beta, \mathrm{r}, \mathrm{i}_{\mathrm{g}}\right)
$$

The above is worth noting so far the implication on macroeconomic stability of NPA is concerned.

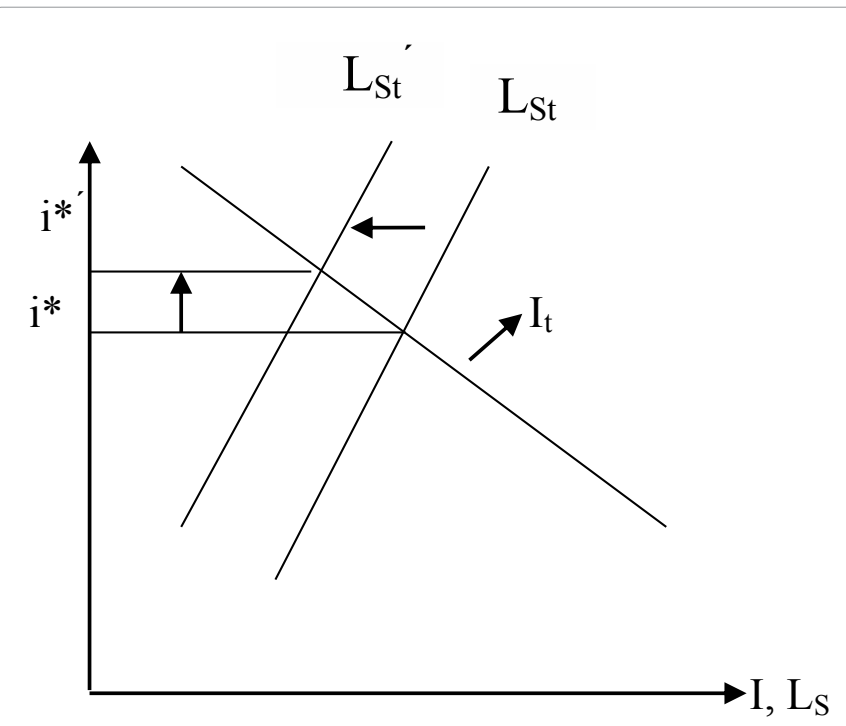

Figure 3: Interest rate equilibrium in presence of NPA. 


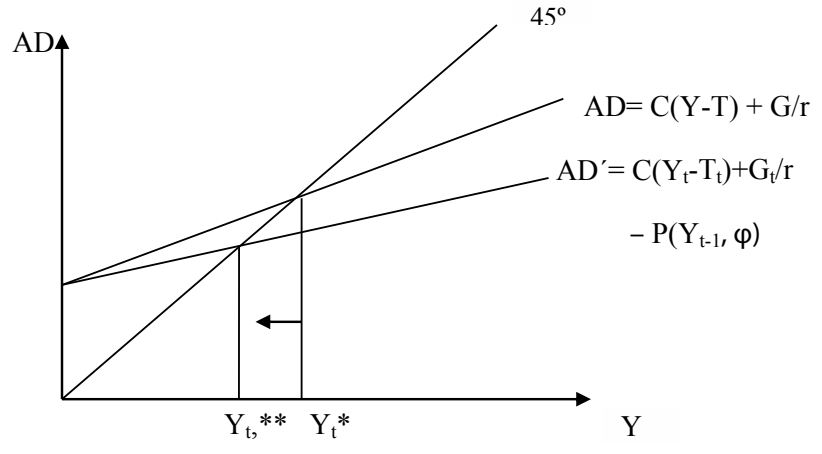

Figure 4: Aggregate output equilibrium in presence of NPA.

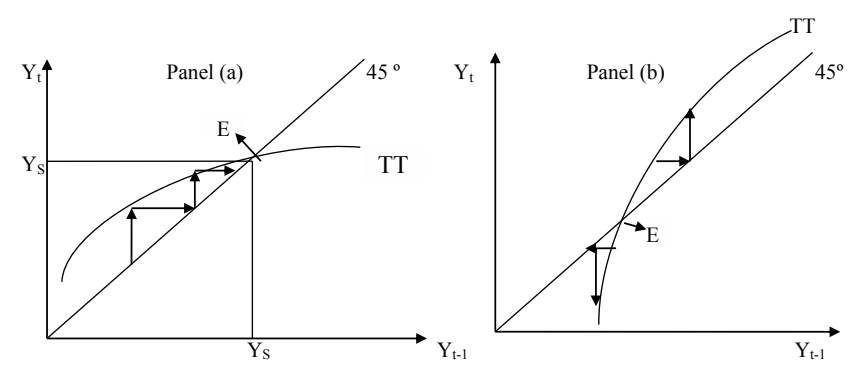

Figure 5: Stability of system in presence of NPA.

Now we can derive the extent to the $\mathrm{Y}$ gets contracted following the rise in the NPA accumulation by comparative static operation, where we differentiate NPA adjusted goods market equilibrium condition totally. Thus we have: $\mathrm{dY}_{\mathrm{t}}=\mathrm{C}^{\prime} \mathrm{dY} \mathrm{t}_{\mathrm{t}}-\mathrm{P}^{\prime} \mathrm{d} \mathrm{\textrm {Y } _ { \mathrm { t } - 1 }}$

$$
\text { or, } \mathrm{dY}_{\mathrm{t}} / \mathrm{dY}_{\mathrm{t}-1}=(-)\left[\mathrm{P}^{\prime} /\left(1-\mathrm{C}^{\prime}\right)\right]>0 \text {, since } \mathrm{P}^{\prime}<0 \text {. }
$$

The result derived above connotes to the self-propagating or selfperpetuating nature of effective demand problem and this happens due to the accumulation of NPA. In other words, a sudden fall in effective demand results in the overproduction and excess capacity accumulation making it difficult for the firms to refinance the loans which in turn leads to the bad debt in the banks [4]. Consequently, the banks need to set aside a part of addition deposits as the provision for such bad debt and henceforth are left with fewer funds to create credit paving way to the rise in interest rate and the fall in the investment. This is how the problem bad loans can catapult an economic system into recession and makes it more vulnerable as well. Thus, any recession breaking out in the economy gets accented and magnified in presence of the NPA because of the increased provision for loss that bank are required to keep in face of loan defaults and resultant contraction of lending. This phenomena can be formally regarded as the problem of effective supply failure which is also a reason why an economic might encounter recession.

\section{Stability of System}

The stability of an economic system vis-a-vis NPA has been analysed in Figure 5 where the TT schedule depicts difference eqn. (3) manifesting the evolution of real aggregate output over time given the parameters $\beta, \varphi, r$ and $i_{g}$ with the $45^{\circ}$ line being used as the reference to determine the steady state equilibrium shown by point $\mathrm{E}$. Given that $\mathrm{dY}_{\mathrm{t}} / \mathrm{dY}_{\mathrm{t}-1}$ is positive one can think of two possibilities: (1) $\mathrm{dY}_{\mathrm{t}} / \mathrm{dY}_{\mathrm{t}-1}>1$ and (2) $\mathrm{dY}_{\mathrm{t}} / \mathrm{dY}_{\mathrm{t}-1}<1$ where possibility (1) has been explained in panel (a) and possibility (2) has been explained in panel (b). Now as shown in panel (a), a rise in $Y_{-1}$ from the point below steady state $E$ leads to rise in $\mathrm{Y}$ and this retunes the economy to the steady state [5]. However, as panel (b) shows a rise in $\mathrm{Y}_{\mathrm{t}-1}$ results in rise in $\mathrm{Y}$ and this continues for ever leading to divergence from the steady state and a fall in $\mathrm{Y}_{-1}$ leads to the fall in $\mathrm{Y}$ with this fall being perpetual. Therefore when condition (2) is valid a contraction of real output arising out of the accumulation of NPA turns out to self-sustaining thereby making the recession a prolonged phenomenon.

If the system happens to be stable then the change in the parameters contained in eqn. (3) will reflect the transition of the economy by one steady state to another as shown in Figure 6; where a rise in profit expectation indicated by increase in $\beta$ results in the upward shift in TT schedule from TT to TT' and thereby an increase in the steady state output from $Y_{S}$ to $Y_{S}^{\prime}$. This is because a rise in profit expectation in periods incentivises more investment and in turn leads to increase in the output in the same period. Now such an increase will lower possibility of bad loan reducing the loss provision for the period $s+1$ allowing for an increase in loanable capacity of the commercial bank and thus a fall in interest rate, a rise in investment and a rise in output. The process of multiplication of output will go on until the economy converges to a new a steady equilibrium $\mathrm{E}^{\prime}$.

Similarly, an adverse supply shock to the loan market i.e., a fall in $\varphi$ makes the economy travel to the new steady state equilibrium with lower $\mathrm{Y}$, given the system is stable.

\section{Model II}

In model II we depart from the closed economic framework analysed so far by inducting an external sector comprising net export and net capital inflow. This apart, we leave the exchange rate to be freely determined by the interplay of market forces in the foreign exchange market [6]. Moreover, the net capital inflow has been kept exogenous in the in the sense it is not sensitive to the interest rate differential between the home and the foreign country. However, this transition leaves the loan market intact and the context of foreign repercussion has been left aside in the light of the small country assumption. below:

Therefore the restated goods market equilibrium is as illustrated

$$
\mathrm{Y}_{\mathrm{t}}=\mathrm{C}\left(\mathrm{Y}_{\mathrm{t}}-\mathrm{T}_{\mathrm{t}}\right)+\mathrm{G}_{\mathrm{t}} / \mathrm{r}-\mathrm{P}\left(\mathrm{Y}_{\mathrm{t}-1}, \varphi\right)+\mathrm{NX}\left(\mathrm{P}^{*} \mathrm{e} / \mathrm{P}, \mathrm{Y}_{\mathrm{t}}, \mathrm{Y}_{\mathrm{t}}^{\mathrm{F}}\right),
$$

where $\mathrm{NX}\left(\mathrm{P}^{\star} \mathrm{e} / \mathrm{P}, \mathrm{Y}_{\mathrm{t}}, \mathrm{Y}_{\mathrm{t}}^{\mathrm{F}}\right)$ refers to the net export which depends on real

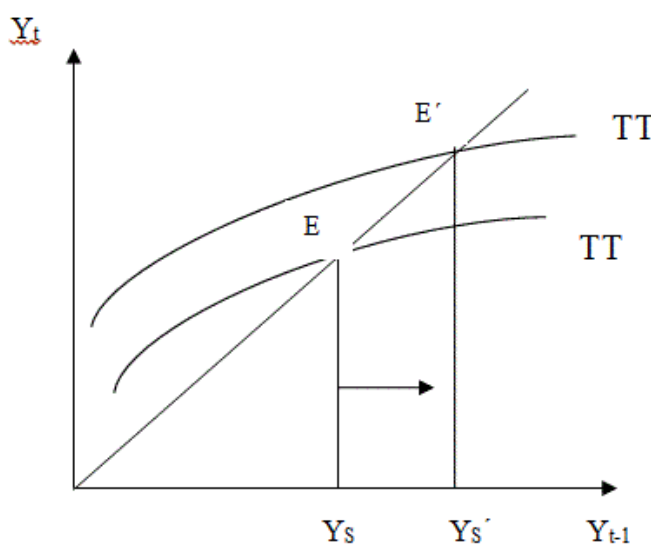

Figure 6: Steady state equilibrium for a stable system in presence of NPA. 


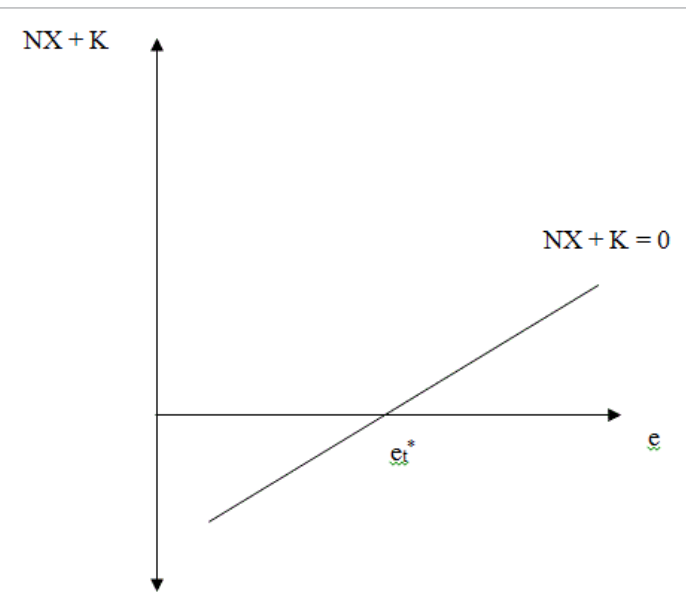

Figure 7: Equilibrium exchange rate in a closed economy.

exchange rate $\left(\mathrm{P}^{\star} \mathrm{e} / \mathrm{P}\right)$, domestic output and foreign output $\left(\mathrm{Y}_{t}^{*}\right)$ held exogenous and $\mathrm{P}^{*}, \mathrm{P}$ are the domestic and foreign price level assumed to be fixed.

Now given that the exchange rate is flexible enough to adjust for the foreign exchange market, the Balance of Payment comes into equilibrium concomitantly with foreign exchange market under the following condition.

$\mathrm{NX}\left(\mathrm{P}^{\star} \mathrm{e}_{\mathrm{t}} / \mathrm{P}, \mathrm{Y}_{\mathrm{t}}, \mathrm{Y}_{\mathrm{t}}^{*}\right)+\mathrm{K}=0$, where $\mathrm{K}$ is the exogenous net capital inflow expressed in terms of domestic goods. Here from the equilibrium exchange rate gets determined for the market clearing $\mathrm{Y}_{\mathrm{t}}$ (as defined by eqn. (3)) as well as in the Figure 7.

$$
\mathrm{e}_{\mathrm{t}}^{*}=\mathrm{g}\left(\mathrm{Y}_{\mathrm{t}-1,} \varphi, \beta, \mathrm{r}, \mathrm{i}_{\mathrm{g}}, \mathrm{P}^{*}, \mathrm{P}, \mathrm{Y}_{\mathrm{t}}^{*}\right) \ldots . .
$$

\section{Conclusion}

The economic and mathematical models backing the phenomenon of NPAs is explained well which is handled as an Primary Object of this research Work. In this regard the basic Keynesian economics is utilised to study the behaviour of NPAs at the macroeconomic level and hence the equilibrium Exchange rate explaining the Market Clearing $\mathrm{Y}_{t}$ which is well explained in the eqn. (3) is further consolidated in the Final equation which gives the clear idea for understanding the research work on the NPA behaviour in the Global Economy.

\section{References}

1. Hyman Mynsky(1992) Financial Instability Hypothesis.

2. Dornbusch and Fischer (1997) Macroeconomics.

3. Knut S, Peter JH (2006) Mathematics for Economic Analysis.

4. Harland Whitmore (1997) World Economy Population Growth and the Global Ecosystem.

5. International Monetary Fund (2015)Global Financial Stability Report, April 2015: Navigating Monetary Policy Challenges and Managing Risks.

6. Thomas P (1997)The Dynamics of the Wealth Distribution and the Interest Rate with Credit Rationing. The Review of Economic Studies 64: 173-189. 